\title{
РЕЦЕНЗИИ
}

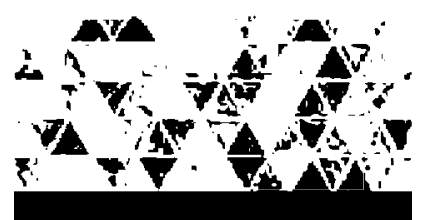

AFISTOTRE AHD EARLY CHRISTIAH THOUGHA

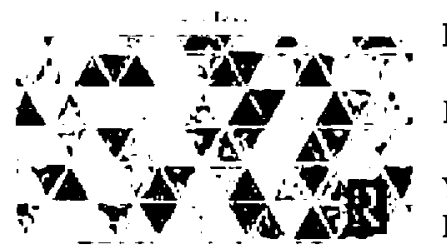

\section{ARISTOTLE AND EARLY CHRISTIAN THOUGHT}

Studies in Philosophy and Theology in Late Antiquity; 6

Mark Edwards

London: Routledge, 2019.226 p.

ISBN 978-11-38-69799-7

УДК 82-95 (1(091))

DOI: $10.31802 /$ GB.2021.41.2.018

Данная книга представляет собой историко-философское исследование о начальном периоде освоения Аристотеля христианами и является шестым изданием, вышедшим в молодой (с 2013 г.) серии «Studies in Philosophy and Theology in Late Antiquity» лондонского издательства Routledge. Автор книги (он же один из редакторов упомянутой серии) тьютор по богословию колледжа Christ Church и профессор раннехристианских исследований факультета Теологии и религии Оксфордского университета М. Эдвардс - известен в первую очередь благодаря своим популярным работам по истории раннего христианства и патристической философии ${ }^{1}$.

По всей видимости, издательство Routledge изначально планировало выпустить в свет парное исследование, посвящённое рецепции раннехристианской мыслью двух крупнейших представителей античной философской традиции - Платона и Аристотеля² ${ }^{2}$ В отличие

1 В личном профиле на сайте Оксфордского университета упомянуты следующие книги М. Эдвардса: Catholicity and Heresy in the Early Church. Aldershot, 2009; Words and Images in Late Antique Talk of God. Aldershot, 2012; Image, Word and God in the Early Christian Centuries. London, 2013; Religions of the Constantinian Empire. Oxford, 2015; Visions of God and Ideas on Deification in Patristic Thought. London, 2016; Origen Against Plato. Aldershot, 2017.URL: https://www.theology.ox.ac.uk/people/professor-mark-edwards-0\#/ 
от издания о Платоне, представляющем собой сборник статей разных авторов, книга М. Эдвардса отличается сознательным методологическим отказом от стратегии коллективного исследования. Автор вполне резонно отмечает в предисловии, что совместные усилия учёных хотя и позволяют добиться детальной проработки материала, но сам исследовательский проект при этом непременно делается более дробным (р. $\mathrm{X})^{3}$. Тем не менее, достаточно широкий временной охват (от нач. II в. до сер. VI в.) на двухстах с небольшим страницах текста сказался в первую очередь на цельности исследования самого М. Эдвардса. Книга оставляет впечатление беглого точечного обзора, которое несколько сглаживается лишь за счёт общих историко-богословских экскурсов, посвящённых проблематике конкретных глав.

Книга состоит из предисловия, девяти глав, послесловия, библиографии и индексов.

Первые две главы - «Философия Аристотеля» (р. 1-18) и «Аристотель во II в.» (р. 19-37) - в самых общих чертах знакомят читателя с жизнью и корпусом сочинений основателя Ликея, а также главными тенденциями аристотелизма в раннем Перипате, среднем платонизме и отдельно - у Плутарха Херонейского и Александра Афродисийского. Сразу оговаривается, что в обзоре сочинений Стагирита рассматриваются лишь те, которые «сыграли роль в формировании и уточнении церковного учения о творении, воплощении, Святой Троице и бессмертии души» (р. 3). Как не отвечающие этой цели опускаются риторика, поэтика, политика, этические и зоологические трактаты Аристотеля. Такой подход представляется едва ли оправданным хотя бы потому, что тем самым из нашего поля зрения полностью выпадает свт. Василий Великий и его Беседы на Шестоднев, очень богатые материалом для обсуждаемой темы (как, впрочем, и другой великий Каппадокиец - свт. Григорий Богослов, рассмотрению которого автор тоже не уделяет должного внимания).

in Late Antiquity/ ed. by P. G. Pavlos, L. F.Janby, E. K. Emilsson, T. Th. Tollefsen. London, 2019. (Studies in Philosophy and Theology in Late Antiquity; vol. 5).

3 Достаточно вспомнить колоссальный по предпринятым усилиям, но совершенно беспомощный и малоинструктивный по своим результатам опыт исследования «Ovंбía в греческой философии от ее начал до Аристотеля», выполненный девятнадцатью высокопрофессиональными под эгидой Centre d'études aristotéliciennes de l'Université de Liège в отсутствии общих методологических установок и чётких договорённостей о рабочих подходах к материалу. См.: Шичалин Ю.А. Рец. на кн.: «Ousia» dans la philosophie grecque des origines à Aristote. Travaux du Centre d'études aristotéliciennes de l'Université de Liège / ed. A. Motte, P. Somville, M-A. Gavray, A. Lefka, D. Seron. Louvain-La-Neuve: Peeters, 2008. IV+494 р.// Вестник ПСТГУ. Серия I: Богословие. Философия. 2009. Вып. 2 (26). С. 112-119. 
Более того, представление о подобной узости и ограниченности христиан в их интересе к Аристотелю является скорее расхожим штампом и вряд ли способствует непредвзятому и исторически корректному пониманию процесса рецепции перипатетической философии.

В качестве, очевидно, введения и подготовки к основной части работы автор знакомит читателя с нюансами аристотелизма как ранних перипатетиков (Стратон из Лампсака, Ксенарх Селевкийский, Боэт из Сидона), так и среди средних платоников (Алкиной и Альбин, Аттик и Апулей). Несомненно, это имело бы смысл при последующем скрупулёзном историко-филологическом анализе встречающихся аллюзий у более поздних авторов, поскольку снабдило бы исследователя широким контекстом бытования текстов Аристотеля и помогло бы вскрыть пути знакомства христиан с философией Перипата. Однако книга М. Эдвардса такого анализа не предполагает, а без этого сведения о разных тенденциях по отношению к Аристотелю в философской среде повисают в воздухе.

К рассмотрению Аристотеля, собственно, в христианской традиции М. Эдвардс приступает только в третьей главе («Аристотель и доникейское христианство»). Опуская в своём обзоре апологетов, кроме Тертуллиана, сочинения которого «give little evidence of a close reading of Aristotle» (р. 38), автор останавливается на св. Ипполите Римском, Клименте Александрийском и Оригене.

М. Эдвардс хорошо ориентируется в исследовательской литературе, с опорой на которую он в основном формулирует свои выводы ${ }^{4}$. Принимая "scholarly consensus» (р. 43) в отношении источников, которыми мог пользоваться святой Ипполит для критического обзора философии Аристотеля в своём «Опровержении всех ересей», М. Эдвардс говорит об одном или нескольких «языческих посредниках», причём платоновского толка, послуживших основой для его труда. Точно также автор отказывает в непосредственном знакомстве, по крайней мере, с эзотерическими сочинениями Аристотеля и Клименту Александрийскому, ссылаясь на результаты исследований известного специалиста по нему - Э. Э. Кларк (р. 44-46). В отношении

4 Иногда, впрочем, не указывая источников, что вызвало справедливое недоумение у одной из исследовательниц при знакомстве с книгой: «In the Metaphysics commentary, "when Origen says of the Son that 'there was not when he was not', he would seem to have borrowed his locution from Alexander" (p. 34) - as I argued in the article mentioned above, curiously not cited at this point though Edwards mentions it elsewhere» (Ramelli I. L. E. Review on: Edwards M. Aristotle and Early Christian Thought // JTS. NS. 2020. Vol. 71. P. 2). 
Оригена автор считает, что возможно говорить о его «знакомстве с перипатетической традицией, хотя и не с сочинениями её основателя» (р. 47). К этому выводу М. Эдвардс приходит, сравнивая аргументы Оригена о Промысле и свободе воли с соответствующими аргументами Александра Афродисийского в его полемике со стоиками, заключая, впрочем, что «родство языковых выражений не всегда свидетельствует о тождестве мысли» (р. 53). Таким образом, даже в Оригене мы в лучшем случае можем видеть лишь «подсознательные» следы перипатетической школьной мысли (р. 53).

В 4-й главе («Неоплатоническая реакция на Аристотеля») автор исследования об Аристотеле в патристике вновь целиком и полностью обращается к Аристотелю у языческих философов античности. Глава открывается пересказом трёх действительно ключевых в отношении Аристотеля у Плотина трактатов $O$ родах сущего ${ }^{5}$, сжато приводится содержание Исагоги и Комментария к Категориям Порфирия, а также Комментария к Категориям Дексиппа. Всё изложенное резюмируется следующим выводом:

«Слияние (fusion) аристотелевской и платоновской мысли было почти полностью завершено в Эннеадах, за исключением того, что Плотин отвергал онтологию, предполагавшгуюся логикой Органона» (p. 74).

Не входя здесь в сложную дискуссию о рецепции Аристотеля Плотином, заметим лишь, что Эннеады полны внутренней скрытой полемики с философией Аристотеля по самым разным вопросам. Не в последнюю очередь нужно сказать, что среди искусно изображённых в известной метафоре Плотина философских школ античности в качестве различных птиц, философии Аристотеля вовсе не отводится места 6 . И если уж говорить о принципиальном включении Аристотеля в программу школы платоников, то это произошло именно при Порфирии, а впоследствии было закреплено Ямвлихом. Но и в данном контексте термин «слияния» не представляется уместным: поздние платоники отводили философии Аристотеля свог, вполне определённую роль пропедевтики к философии Платона.

Следующая глава («Аристотель и Троица в четвёртом веке») вновь погружает читателя в контекст христианского богословия и открывается общими рассуждениями о том, что усвоение отцами Церкви некоторых образовательных установок того времени (теория элементов, учение

5 Plotinus. Enneas VI, 42-44, 1-3.

6 Plotinus. Enneas V, 5, 9.1:7-21. 
о четырёх родовых добродетелях, шарообразность земли и проч.) само по себе не делает их аристотеликами или платониками (р. 78). В главе рассматриваются как греческие авторы (свт. Афанасий Александрийский, Евсевий Кесарийский, свт. Кирилл Александрийский), так и латинские (Марий Викторин и блж. Августин). Впрочем, появление в этой главе параграфов, посвящённых христианам, писавшим по-латыни, как представляется, вызвано желанием сообщить книге некий характер универсальности, но вместо этого делает её более поверхностной и популярной.

К сожалению, автор не отводит какой-либо более-менее значимой роли Евсевию Кесарийскому, в то время как его Евангельское приуготовление заслуживает самого пристального внимания - в первую очередь с точки зрения того, из каких источников христиане того времени могли знакомиться с Аристотелем. Объединяя Евсевия и свт. Афанасия Великого в один параграф размером в страницу, М. Эдвардс скупо характеризует знакомство Кесарийского епископа с Аристотелем как «непоследовательное и почти наверняка опосредованное» (p. 80). Чуть большего внимания удостаивается свт. Кирилл Александрийский. Автор кратко воспроизводит его основные аргументы в полемике с Евномием и заключает: «Кирилл демонстрирует себя прилежным и проницательным учеником Исагоги, однако на этом основании мы должны с осторожностью приписывать ему любое непосредственное знакомство с Аристотелем» (p. 91).

Предлагая набросок учения Мария Викторина о Святой Троице, автор традиционно отмечает в нём платоническое влияние, а также «элементы независимого прочтения Аристотеля» (р. 83), в чём мы, конечно, можем не сомневаться, хотя бы имея в виду его перевод Категорий, благодаря которому, возможно, знакомился с философией Стагирита и блаженный Августин.

Шестая глава («Григорий Нисский и Аристотель») посвящена рассмотрению «трансформации аристотелевской телеологии и логики в аргументах Григория Нисского" (р. 98). Автор начинает с резюме евномианской доктрины и затем переходит к реконструкции аргументации самого святого. Главный вывод, к которому приходит М. Эдвардс в этой части исследования, - переосмысление свт. Григорием термина

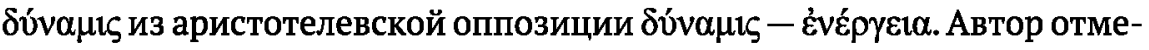

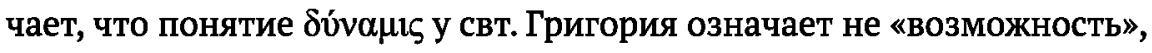
а уже «реализацию этой возможности» - некую силу и мощь, присущую совершенной природе. Сила всех Трёх Божественных Ипостасей 
едина, поскольку относится к единой Божественной сущности. Тем самым свт. Григорий первым, как отмечает автор, включает понятие $\delta v-$ vанц в триадологию (р. 102).

Форму фактически самостоятельного исследования имеет приложение к шестой главе «Hypokeimenon в учении Григория Нисского о Троице» (р. 116-128), в котором автор разбирает несколько фрагментов из трактата Против Евномия, пытаясь определить и соотнести значение этого аристотелевского концепта у святого в сравнении с терми-

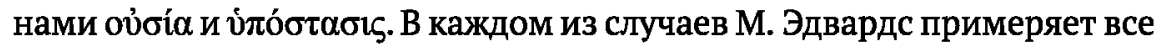

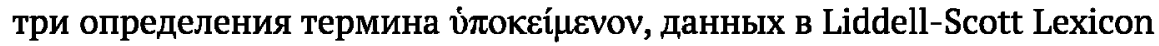
(1. the substrate; 2 the particular object; 3 . the logical subject), не всегда, впрочем, приходя к какому-то определённому выводу.

Седьмая глава посвящена «Аристотелю и христологическим спорам» (р. 129-170). Здесь кратко рассматривается антропология Немесия Эмесского, ересь Севира и ответ на неё Леонтия Византийского.

В вопросах учения о душе, как отмечает автор, Немесий отдаёт явное предпочтение Платону, критикуя многие положения $O$ душе и О происхождении животных Аристотеля. Некоторые рассуждения Немесия представляются М. Эдвардсу «поверхностными и почерпнутыми из учебников", однако автор признаёт, что фундаментальные аристотелевские положения о природе души явно захватывают интерес Эмесского епископа и «свидетельствуют о внимательном прочтении текстов, которые всё ещё вызывают споры» (р. 131).

Приятно отметить, что в книге подчёркивается филологическая несостоятельность расхожего штампа об «инновационной доктрине воиспостасности» (р. 137-138), которую якобы предложил Леонтий Византийский. Анализируя его полемику с Севиром с точки зрения использования терминологии и правил аристотелевской логики, автор утверждает, что она «едва ли могла быть результатом внимательного прочтения Аристотеля» (р. 145). Со ссылкой на других исследователей М. Эдвардс отмечает, что аргументация Леонтия не может быть согласована ни с Органоном Аристотеля, ни с его позднейшими комментаторами (р. 145).

Две последние главы книги целиком посвящены Иоанну Филопону (ch. 8) и Боэцию (ch. 9).

Акцент, который делает автор, называя Иоанна Филопона «первым христианином, комментировавшим аристотелевский корпус сочинений» (р. 149), на самом деле скорее вводит в заблуждение: преподавание школьных курсов по текстам Аристотеля в Александрии 
было совершенно традиционным и не имело отношения к христианству ни у Филопона, ни у христиан Элиаса и Давида. В остальном Иоанн Филопон представлен автором достаточно традиционно. М. Эдвардс отмечает два периода его творчества (до и после эдикта императора Юстиниана 529 г.) и подробно останавливается на теме «Творение versus вечность», пересказывая его известный трактат Против Прокла по вопросу о вечности мира (р. 152-159).

После последовательного обзора аргументов против вневременного понимания акта творения и критики некоторых восходящих к Аристотелю философских положений, автор переходит к рассмотрению позднего сочинения Иоанна Филопона О творении мира, демонстрирующего уже иное отношение к Стагириту. Здесь М. Эдвардс насчитывает около пятнадцати прямых упоминаний Аристотеля, а также достаточное количество узнаваемых отсылок к его философии (человек как единство души и тела, несубстанциональность тьмы и др.), причём в одобрительном тоне (р. 160). Этот факт очевидной перемены Иоанна Филопона к Аристотелю автор никак не комментирует, хотя вопрос напрашивается сам собой. Размышляя над этой проблемой, современные исследователи говорят о вероятном смягчении Иоанна в неприятии Аристотеля под влиянием почитавших Философа монофизитов $^{7}$. В завершении главы автор не без доли сочувствия и оправдания излагает богословские воззрения Иоанна Филопона, отвергнутые ортодоксальным христианством.

По трудолюбию в толковании наследия Аристотеля для Рима М. Эдвардс называет Боэция «собственным Филопоном» западного богословия, не запятнавшим себя в ереси (р. 171). В девятой главе автор перечисляет переводческие и комментаторские заслуги Боэция, приводит резюме двух его комментариев к Введению Порфирия и анализирует проблему времени и божественного предведения в Утешении философией.

Боэций действительно стал одним из авторитетнейших наставников в античной философии и логике для всего латинского Средневековья, поэтому обращение к нему в последней главе книги вполне соответствует мысли автора, обозначенной в послесловии: наметить новое начало бытования аристотелевских текстов в католическом и исламском мире и направить к нему любознательного читателя (р. 195).

7 См.: Шичалин Ю. А. Иоанн Филопон // Античная философия: Энциклопедический словарь. М., 2008. С. 399. 
Посвящённая важной и малоизученной теме книга М. Эдвардса сразу получила отклики в научном сообществе. С достаточной долей энтузиазма она была воспринята редактором «Руководства к рецепции Аристотеля в Античности» ${ }^{8}$ голландского издательства Brill А. Фальконом, отмечающим, что книга М. Эдвардса восполняет лакуну этой части аристотелеведения и способствует необходимой ориентации на широкой неизведанной территории 9 . Другой учёный видит сильную черту исследования в намеренном отказе автора от разговора о «христианском аристотелизме» авторов рассматриваемого периода ${ }^{10}$. В то же время главные вопросы о рецепции Аристотеля христианами пока так и не поставлены: как, через какие именно тексты и школы происходит знакомство и принятие его мысли, - что справедливо провоцирует соответствующую реакцию коллег М. Эдвардса:

«Would it not be more useful to track and describe the multiple ways and degrees in which early Christian thinkers engaged with the Aristotelian legacy? Would it not be more useful to understand the category of "Aristotelian" as a spectrum, rather than as a binary opposition Aristotelian/non-Aristotelian?»11

Несмотря на популярный характер изложения, книга, несомненно, является важной вехой в современном изучении аристотелевского наследия у христиан. Особую ценность представляют библиографические сводки к каждому разделу и библиография в конце книги (р. 197213). Знакомство с изданием будет полезно как светским исследователям, так и богословам, намечая непроторенные пока ни первыми, ни вторыми пути освоения перипатетической философии христианской Церковью.

\section{Иеромонах Дометиан (Курланов)}

8 Brill's Companion to the Reception of Aristotle in Antiquity / ed. by A. Falcon. Leiden; Boston, 2016. (Brill's Companions to Classical Reception; vol. 7).

9 Falcon A. Rezension von: Edwards M. Aristotle and Early Christian Thought // Sehepunkte. 2019. № 9 (19). URL: http://www.sehepunkte.de/ 2019/09/33099.html

10 Ramelli I.L. E. Review on: Edwards M. Aristotle and Early Christian Thought // JTS. NS. 2020. Vol. 71.P. 2.

11 Sassi N. Aristotle and Early Christian Thought by Mark Edwards (Review) //JECS. 2020.Vol. 28. № 1, Spring. P. 161. 


\section{Библиография}

Brill's Companion to the Reception of Aristotle in Antiquity/ed. by A. Falcon. Leiden; Boston: Brill, 2016. (Brill's Companions to Classical Reception; vol. 7).

Edwards M. J. Catholicity and Heresy in the Early Church. Aldershot: Ashgate, 2009.

Edwards M. J. Words and Images in Late Antique Talk of God. Aldershot: Ashgate, 2012.

Edwards M. J. Image, Word and God in the Early Christian Centuries. London; New York: Routledge, 2013.

Edwards M.J. Religions of the Constantinian Empire. Oxford: Oxford University Press, 2015.

Edwards M. I., Ene D-Vasilescu E. Visions of God and Ideas on Deification in Patristic Thought. London: Routledge, 2016.

Edwards M. J. Origen Against Plato. Aldershot: Ashgate, 2017. (Ashgate Studies in Philosophy and Theology in Late Antiquity).

Edwards M. Platonism and Christian Thought in Late Antiquity / ed. by P. G. Pavlos, L. F. Janby, E. K. Emilsson, T. Th. Tollefsen. London: Routledge, 2019. (Studies in Philosophy and Theology in Late Antiquity; vol. 5).

Falcon A. Rezension von: Edwards M. Aristotle and Early Christian Thought // Sehepunkte. 2019. № 9 (19). [Электронный ресурс]. URL: http://www.sehepunkte.de/2019/09/33099.html (дата обращения 10.03. 2021).

Ramelli I. L. E. Review on: Edwards M. Aristotle and Early Christian Thought // JTS. NS. 2020. Vol. 71. P. 1-7.

Sassi N. Aristotle and Early Christian Thought by Mark Edwards (Review) // JECS. 2020. Vol. 28. № 1, Spring. P. 159-161.

Шичалин Ю. А. Иоанн Филопон // Античная философия: Энциклопедический словарь. М.: Прогресс-Традиция, 2008. С. 398-400.

Шичалин Ю. А. Рецензия на кн.: «Ousia» dans la philosophie grecque des origines à Aristote. Travaux du Centre d'études aristotéliciennes de l'Université de Liège. / ed. A. Motte, P. Somville, M.-A. Gavray, A. Lefka, D. Seron. Louvain-La-Neuve: Peeters, 2008. IV+494 p.// Вестник ПСТГУ. Серия I: Богословие. Философия. 2009. Вып. 2 (26). С. 112-119. 